\title{
OS PRONTUÁRIOS DO MANICÔMIO JUDICIÁRIO DO ESTADO DE SÃO PAULO (1897-1930) COMO FONTE PARA O HISTORIADOR: POSSIBILIDADES E LIMITAÇÕES
}

\author{
THE MEDICAL RECORDS OF THE JUDICIAL ASYLUM OF THE \\ STATE OF SÃO PAULO (1897-1930) AS A SOURCE FOR A \\ HISTORIAN RESECHEAR: POSSIBILITIES AND LIMITATIONS
}

DOI: http//dx.doi.org/10.15448/21778-3748.2018.2.26267

\author{
Augusto Nalini Aigner de Paula \\ Graduado em História - UNIFESP \\ augusto.aigner@hotmail.com
}

\begin{abstract}
RESUMO: $\mathrm{O}$ artigo em questão trata dos prontuários psiquiátricos do antigo Manicômio Judiciário do Estado de São Paulo, com recorte cronológico de 1897 a 1930, custodiados pelo Arquivo Público do Estão de São Paulo (APESP). Esses prontuários foram descritos através de um projeto do grupo Programa de Ensino Tutorial (PET) - História/Unifesp, iniciado em 2013, para a produção de um instrumento de pesquisa. O artigo analisa essa espécie documental, discutindo suas possibilidades e limitações como fonte de pesquisa, levando em conta a natureza de produção dessa fonte, mas refletindo sob a perspectiva da historiografia. Para tanto, foi fundamental uma breve introdução da trajetória do acervo documental, a história administrativa da instituição e uma análise da estrutura desse tipo documental ao longo das três décadas do recorte cronológico proposto. Inclusive, tratando-se de uma documentação sensível, todos os cuidados com a memória dos pacientes e seus familiares foram respeitados.
\end{abstract}

Palavras chave: Prontuários Médicos; Manicômio Judiciário; São Paulo

\begin{abstract}
This paper deals with the psychiatric medical records of the former São Paulo Judicial Asylum, with a chronological snippet from 1897 to 1930, guarded by the Arquivo Público de São Paulo (APESP). These records were described through a project of the Programa de Ensino Tutorial (PET) - História/Unifesp, started in 2013 , to produce a research instrument. The article analyzes this documentary species, discussing its possibilities and limitations as a source of research, considering the nature of production of this source, but reflecting from the perspective of historiography. In order to do so, it was fundamental to briefly introduce the trajectory of the documentary collection, the administrative history of the institution and an analysis of the structure of this documentary type over the three decades of the proposed chronological cut. Even in the case of sensitive documentation, all the memory care of the patients and their relatives were respected.
\end{abstract}

KEYWORDS: Medical Records; Judicial Asylum; São Paulo.

\section{INTRODUÇÃO}

O presente artigo tem como objetivo refletir sobre os prontuários psiquiátricos do antigo Manicômio Judiciário do Estado de São Paulo, com recorte cronológico de 1897 a 
1930, custodiados pelo Arquivo Público do Estado de São Paulo (APESP), dando continuidade a um dos projetos do grupo PET-História ${ }^{1}$, iniciado em 2013 e que desenvolvia a coleta de dados dos prontuários para a produção de um instrumento de pesquisa que pudesse auxiliar pesquisadores no uso da fonte.

Para além de investigar o que é o prontuário médico do Manicômio, este trabalho discute suas possibilidades e limitações quando apropriados como fontes de pesquisa. Posto isso, antes de tratar desse objeto, é importante contextualizar suas origens e conhecer um pouco sobre a instituição que produziu essa documentação, bem como conhecer seu percurso até a chegada ao APESP.

O Manicômio do qual falamos faz parte das instalações do Complexo Hospitalar do Juquery, inaugurado em $1898^{2}$ juntamente com a primeira colônia agrícola masculina, na gestão do alienista Francisco Franco da Rocha. Já o Manicômio Judiciário foi criado em 26 de dezembro de 1927 - quando Júlio Prestes ocupava o cargo de governador de São Paulo -, como "annexo ao Hospital de Alienados de Juquery e subordinado à mesma administração desse estabelecimento"3 destinado à "internação e ao tratamento : I) - dos detentos que apresentem perturbações mentaes, antes ou depois da condemnação; II) - dos insanos a que se refere o art. 29, última parte, do Codigo Penal", recebendo pacientes de ambos os sexos. Apesar da criação tardia, a produção dos prontuários dessa instituição antecede a data mencionada: como veremos adiante, os prontuários do Manicômio datam desde 1899 (Arquivo Público Do Estado de São Paulo, Manicômio Judiciário ${ }^{4}$, caixa 1, prontuário DAP 192).

Em 2012, após um princípio de incêndio, o APESP providenciou o recolhimento da documentação e a incorporação da mesma em seu acervo permanente. Nos finais de 2012, o APESP e o grupo PET-História Unifesp firmaram um acordo para iniciar a descrição da documentação, ficando o grupo PET responsável pela coleta das informações afim de alimentar um banco de dados que serviria como instrumento de pesquisa.

\footnotetext{
${ }^{1}$ O Programa de Ensino Tutorial, fomentado pelo Ministério da Educação, é desenvolvido por um grupo de estudantes da graduação, exclusivamente, e conta com a tutoria de um docente, com o objetivo de desenvolver atividades e projetos que materializam o tripé: ensino, pesquisa e extensão. Existem grupos PET em diferentes instituições do Ensino Superior, públicas e privadas, ligados a um curso específico, como o caso do PET-História da Universidade Federal de São Paulo, ou a vários cursos, os chamados PET temáticos. Cada grupo pode contar com doze discentes bolsistas e seis voluntários, além de um docente tutor. Esses bolsistas são selecionados através de um processo seletivo previsto no regimento dos grupos PET.

${ }^{2}$ A resolução de tombamento do Complexo Hospitalar do Juquery trata brevemente do contexto de criação dessa colônia e do Hospital Central, além disso apresenta plantas e mapas do complexo hospitalar que foi tombado em 2011 pelo CONDEPHAAT.

${ }^{3}$ Lei $\mathrm{n}^{\circ} 2.245$, de 26 de dezembro de 1927. Disponível em: http://www.al.sp.gov.br/repositorio/legislacao/lei/1927/lei-2245-26.12.1927.html. Acessado em: 14/10/2015 ${ }^{4}$ Daqui por diante referenciado como APESP/MJ.
} 
A documentação sob custódia do Arquivo é apenas uma parte do acervo do Manicômio. Parte ainda se encontra em Franco da Rocha, no Arquivo do Hospital Psiquiátrico do Juqueri, atualmente chamado de Hospital de Custódia e Tratamento Psiquiátrico Professor André Teixeira Lima. É preciso destacar ainda que os prontuários referentes aos anos de 1900, 1901 e 1902 também não estão presentes no conjunto documental custodiado pelo Arquivo. Provavelmente ficaram para trás na transferência da documentação em 2012, ou foram destruídos durante um incêndio ocorrido entre 1999 e 2000 que levou à perda de inúmeros prontuários do Hospício do Juqueri.

Desde 2013, o grupo PET realizou o trabalho de coleta de dados para a alimentação de uma planilha com as informações dos 351 prontuários presentes no recorte do projeto de 1897 a 1930, etapa essa concluída no início de 2015. Encontramo-nos então na fase final do projeto, fazendo uso das informações para a produção de artigos com temáticas variadas, que lidam com as informações que os prontuários de uma instituição como essa pode oferecer para o historiador. Antes de trabalhar com o que o prontuário informa sobre o paciente, o ponto de partida deste artigo é refletir sobre o próprio prontuário como fonte e objeto de análise.

O texto foi dividido em três partes. Na primeira, são apresentadas a tipologia documental e o tipo de produção acadêmica que utilizou os prontuários como fonte. $\mathrm{Na}$ segunda parte, o olhar volta-se para a estrutura do prontuário médico ao longo das três primeiras décadas do século XX, buscando entender o que o prontuário revela sobre si mesmo e quais eram as informações relevantes para assistência psiquiátrica no período. Na terceira parte, faz-se uma reflexão sobre as informações contidas no prontuário, tais como as dinâmicas e problemas da instituição, interações com a família do paciente, poemas e desenhos. Nesse momento, enfoco as possibilidades do prontuário enquanto registro de um projeto de saúde pública e ordem social, iniciado antes da virada do século, mas que encontrou nas primeiras décadas do XX um ambiente fértil para o desenvolvimento.

Por fim, além das datas-limite, mais um critério foi utilizado no trabalho. Foram analisados 28 prontuários, que serviram para a reflexão acerca da estrutura do documento, um para cada ano do recorte temporal, começando em 1897, ano em que o primeiro prontuário foi produzido, e terminando 1930. É preciso destacar ainda os cuidados no uso desse tipo de documento, de modo a garantir a privacidade do paciente e de sua família. Nenhuma informação que pudesse expor a identidade dos pacientes e seus familiares foi utilizada. No sentido de preservar o direito à privacidade e intimidade, os pesquisadores vinculados ao projeto assinaram termo de compromisso e utilizaram iniciais no lugar nos nomes próprios. 
Quando da necessidade de menção a um prontuário específico, usamos a abreviatura do nome e o número da caixa e do prontuário.

\title{
O USO DE PRONTUÁRIOS MÉDICOS
}

Segundo resolução de 2002 do Conselho Federal de Medicina", "prontuário médico" é um documento único em que informações sobre a identificação e antecedentes do paciente, assim com sua trajetória dentro de determinada instituição médica, estão reunidas com a finalidade de permitir a "continuidade da assistência" ao paciente. De forma geral, é composto por seções como: identificação, anamneses, exames físicos, diagnóstico, plano terapêutico; além de exames clínicos, laboratoriais, anatomopatológicos; evolução clínica e prescrição médica. ${ }^{6}$

Apesar de não ser uma tipologia documental nova, a utilização de prontuários médicos em trabalhos e pesquisas que envolvem a história da saúde é relativamente recente e muitas vezes parte da busca de fontes alternativas que permitam observar as instituições, o corpo médico e os pacientes sob perspectivas diferenciadas. Pesquisadores como Maria Clementina Pereira Cunha (1986; 2010), Yonissa Marmitt Wadi (2009) e Claudio Bertolli Filho (1996) são exemplos que há algum tempo vêm buscando o acesso e utilização dessa tipologia documental, partindo desse interesse por fontes primárias alternativas que possibilitem ecoar as vozes de grupos do passado ainda pouco ouvidos. Utilizando as informações reunidas na documentação, eventualmente pode-se atravessar as paredes das instituições médicas:

\begin{abstract}
A ausência de exploração de uma fonte sintetizadora das múltiplas facetas do viver enfermado é um fato que tem encaminhado os historiadores da medicina a vasculhar arquivos na tentativa de localização de núcleos documentais mais consistentes. Há aproximadamente duas décadas tenho partilhado com uma legião de colegas da Academia as dificuldades deste compromisso e de regra todos convergimos para a necessidade de localização de arquivos prontuariais como forma de superação do declarado desconhecimento do paciente na perspectiva histórica. (BERTOLLI, 1996, p. 173)

A utilização dos prontuários médicos se fez fundamental. Além da fala oficial e "verdadeira" dos diretores do hospício registrada em Relatórios ao Presidente da Província, nada mais resta para uma escrita da história sobre os loucos que lá estiveram internados. (SCOTTI, 2001, p. 1).
\end{abstract}

Nos últimos anos, a preocupação e o interesse pela fonte motivaram pesquisadores a tratar o próprio prontuário como objeto de estudo, decompondo sua estrutura e organização,

\footnotetext{
${ }^{5}$ Resolução CFM n ${ }^{0} 1.638 / 2002$. Disponível em: |<http://www.portalmedico.org.br/resolucoes/cfm/2002/1638 2002.htm>, Acessado em: 10/11/15.

${ }^{6}$ Manual de orientação ética e disciplinar, v. 1. $2^{\mathrm{a}}$ ed, Florianópolis, Comissão de Divulgação de Assuntos Médicos-, março 2000. Disponível em: $<$ http://www.portalmedico.org.br/Regional/crmsc/manual/parte3b.htm $>$, Acessado em: 10/11/15.
} 
relacionando-as com as instituições em que foram produzidos, com o objetivo de incorporar essas fontes e suas possibilidades ao trabalho acadêmico. Nesse sentido, destaco o artigo de Bruna da Silveira Viana, que trata das possibilidades de pesquisa no antigo Hospital Colônia Sant'Ana (2013), destacando as condições de acondicionamento de seu acervo de prontuários, a estrutura e organização das sessões do documento, produzindo um banco de dados e um instrumento de pesquisa, metodologia semelhante à utilizada pelo grupo PET-História UNIFESP com o acervo de prontuários do Manicômio Judiciário de São Paulo.

Destaco também a tese de Nádia Maria Weber Santos (2005) cuja proposta é refletir sobre a voz do paciente sobre si mesmo, a loucura e o espaço de confinamento, na realidade, como a própria autora afirma, "os escritos de si”. Para tanto debruça-se, entre em outras coisas, sobre os prontuários dos pacientes do Hospício São Pedro em Porto Alegre e as cartas por eles escritas, descrevendo no processo a estrutura do prontuário, as finalidades dessas cartas e a importância para o trabalho historiográfico. Atrelado a isso, a autora envolve na discussão também os romances e diários produzidos por autores que tiveram a experiência da internação, um dos exemplos foi Lima Barreto. Ainda sobre o Hospício São Pedro, é preciso destacar o artigo de Zelinda Rosa Scotti (2011), sobre os prontuários dessa instituição; nele, a autora apresenta a organização de um banco de dados, destacando na sequência a aplicação das informações reunidas para uma análise social da população internada. Nos três trabalhos, pelo que sugerem as analises, a estrutura e organização dos prontuários são semelhantes e dialogam com o que prevê o Conselho Federal de Medicina.

\section{O PRONTUÁRIO E SUA ESTRUTURA}

De modo semelhante aos prontuários médicos de instituições não psiquiátricas, os prontuários do antigo Manicômio Judiciário utilizam o mesmo método científico investigativo, reunindo informações que permitam ao médico construir as conclusões diagnósticas e acompanhar a evolução do paciente.

De forma geral, os prontuários do Manicômio são divididos em três partes. A primeira é o "arquivo psiquiátrico-criminal", e nela estão reunidas todas as informações relacionadas à identificação do paciente, seus antecedentes, as avaliações dos médicos e os resultados de exames. Na primeira página somos apresentados ao paciente, observando informações básicas como: nome, idade, naturalidade, procedência, estado civil, profissão, religião, instrução, dados étnicos, data de entrada, de saída e a assinatura do médico responsável. Em alguns casos, consta também uma fotografia do paciente registrada no ato da entrada. 
Em seguida, ainda no arquivo psiquiátrico-criminal, existem duas páginas para a anamnese, dividida em quatro itens: balanço genealógico, infância, puberdade e idade adulta. Em cada um desses itens existem campos preenchido pelo médico de acordo com entrevista feita com o paciente, registrando antecedentes pessoais e familiares, traumas, doenças antigas e hereditárias, atentando se o paciente possui familiares com algum transtorno ou "moléstia mental". Em geral esses campos não são totalmente preenchidos, permanecendo muitas lacunas sobre a procedência do paciente. Avançando para a quinta página, consta o item "exame directo" dividido em três tópicos: exame directo, exame somático e exame mental. Nesse último, deparamo-nos com campos que descrevem os sintomas e as condições do paciente, preenchidos de acordo com a avaliação do médico sobre o paciente.

\section{"Arquivo Psiquiatrico-Criminal" 7}

\section{I}

\section{ANAMNESE}

\section{A) Balanço genealógico}

-Estado de saude da família:

-Doenças nervosas e mentaes:

-Alcoolismo:

-Syphilis:

-Particularidades estranhas:

-Crimes:

-Suicidios:

-Consanguinidades:

-Casamentos desproporcionados em edade:

-Acidentes da prenhez materna respectiva:

-Parto laborioso ou espúrio:

\section{B) Infancia}

-Estados nevropathico:

-Convulsões:

-Doenças febris, eruptivas e outros:

-Intoxicações:

-Inicio e condições da marcha e da palavra:

-Desenvolvimento physico:

-Desenvolvimento da Inteligencia e do caracter:

\footnotetext{
${ }^{7} \mathrm{O}$ texto que segue é uma transcrição das páginas do arquivo psiquiátrico criminal. Elas são compostas pelos itens aqui discriminados impressos. Cabia ao médico psiquiátrica preencher os campos baseando-se nas informações fornecidas pelos exames, entrevistas com o paciente, seus familiares.

Para aproximar-se ao máximo das páginas do prontuário, foi decidido manter a forma como itens foram dispostos assim como a grafia original.
} 
-Alterações da evolução normal:

-Perversão dos sentimentos:

.por traumatimo -

.doença -

causas diversas -

-Conducta no meio domestico e na escola:

-Educação em collegio, asylo convento:

-Desenvolvimento sexual; nanismo precoce:

-Habitos anormaes:

-Colera:

-Mentiras caluniosas:

-Furtos:

-Assombramentos:

-Terrores noturnos:

-Pesadelos:

-Loquacidade hypnagogica:

-Micção no leito:

\section{C) Puberdade:}

-Parada de desenvolvimento mental:

-Perturbações psychicas transitoriais:

-Convulsões:

-Risos:

-Choros imotivados:

-Primeira menstruação:

-Regra catamenial:

-Primeiras praticas sexuaes:

-Masturbação:

-Ergastenia (por estafa mental, cansaço physico ou exgottamento venereo):

\section{D) Edade adulta:}

-Caracter:

-Regularidade:

-Firmeza:

-Inclinações:

-Ethylismo:

-Jogo:

-Libertinagem:

-Usura:

-Vaidade:

-Philantropia:

-Colleccionismo:

-Instalação na vida:

.protegido ou desajudado -

-Particularidades nos costumes (hábitos, gostos):

-Casamento: 
-Relações com o outro cônjuge:

.lar feliz ou infeliz -

-Quantos filhos vivos:

.condições de sua sobrevivência -

.quantos mortos -

.causa lethal esoecificada -

-Prenhezes a termo; abortada:

seus intervalos -

-Menopausa próxima ou chega:

-Condições de vida:

.trabalho -

-Preocupações de fortuna e bem estar social:

-Doenças infecciosas graves:

.syphilis -

febres eruptivas -

.febre typhica -

febre amarella -

peste -

peneumonia -

.grippe -

.diphteria -

-Intoxicações agudas ou chronica:

.pelo álcool -

.chumbo, arsênico -

.alimentos deteriorados, etc -

-Traumatismos physicos e psychicos, quedas, emoções violentas:

-Doenças nervosas e mentaes antecedentes, fórma, caracter, evolução, duração, tratamento das mesmas:

-Excessos, privações:

-Perversões genésicas:

-Operações cirúrgicas pregressas:

-Accusações e condenações anteriores:

-Actos e crimes attribuidos, informados em processo criminal, narrados pelo examinado:

\section{II}

\section{EXAME DIRECTO}

A)

-Atittude:

-Apresentação:

-Expressão physionomica, mimica: .falada, actuada -

B)

a) Altura

-Corpulencia:

-Musculatura: 
-Atrophias, hypertrophias:

-Desproporções (aleijados, anões):

-Adiposidade:

-Cor da pelle e das mucosas:

-Pelugem:

-Glabrismo:

-Vicios de conformação: pé chato, poly e syndactilia-

-Epispadias:

-Hypospadias:

-Cryptorchidia:

-Asymetrias:

-Orelhas em aza, em ponta, etc:

-Beiço de lebre, guela de lobo, etc:

b) Cabeça:

-Forma, deformações, assymetrias:

-Diametro trasverso:

-Diametro longitudinal:

-Curva transversa biauricular:

-Curva antero-posterior:

-Circunferência total:

-Semicircunferência: anterior, posterior:

-Indice cephalico:

-Altura da face:

-Diametro bizygomatico:

-Tipo facial, índice facial:

-Calvice, canicie:

-Sensibilidade à pressão e percussão:

-Desvios da da face, contracções, tremores:

-Sensibilidade dos pontos nervosos á pressão:

-Reutophilia:

-Cicatrizes:

-Olhos:

-Campo visual:

-Vicios de refracção:

-Estrabismo, daltonismo:

-Lingua e boca: projecção, tremores, grossos ou fibrilares, saburra -

-Dentes excessivos, vícios de implantação, disatema:

-Abobada platina: estreita, iunda, em querena -

-Forma e direção da úvula:

-Prognatismo:

-Nariz: fórmas, desvios do septo -

-Ouvido:

-Olfacto:

-Gosto:

c) Orgams thoraxicos e pelvianos

-Inversões visceraes, desvios, deformações:

-Hernias:

-Pulso: 
-Rythmo respiratório:

.cardiaco -

d) Sensibilidade:

-Tactil:

-Thermica:

-Dolorosa:

-Sentido muscular:

-Sinal de Remberg:

e) Motilidade

-Dynamometria:

-Paralysias:

-Paresias:

-Contracturas:

-Convulsões:

-Tremores:

-Lethargia:

-Catalepsia:

f) Reflexos:

-Pupilar:

-Pharyngeo:

-Rotulisno:

-Abdominal:

-Cremasteriano:

-Plantar:

-Achilleano, etc:

g) Exame a urina

-Reação:

-Toxidex:

-Phosphatos:

-Assucar:

-Albumina:

h) Estado geral da nutrição:

-Auto-intoxicação:

-Perturbações cenesthesicas:

-Somno: insonia -

C) Exame mental:

(Pelo interrogatório e observação de actos e palavras do examinado)

-Noção do tempo, meio:

-Confusão de espirito, alheiamento ao mundo exterior delírio, palavras soltas, mutismo:.

-Humor do examinado, com ou sem correspondência no meio ambiente:

.Alegre, arrogante, folgado, reservado, desconfiado, triste, ancioso, indiferente, colérico, furioso -

-Explicação destes estados pelo arguido: 
-Excitação, depressão angustia:

-Apathia:

-Transforamação da personalidade:

-Ideação:

.tarda, acelerada, tumultuosa, irregular, confusa -

-Attenção, observação:

-Tempo de reação:

-Imaginação:

-Percepção: illusões, alucinações -

-Delírios:

.de perseguição -

.grandeza -

.ruína -

.pecado -

.negação -

.querela -

.possessão demoníaca -

.possessão divina, etc -

-Delírios fixo, imutáveis coerentes, raciocinados etc:

-Impulsões:

-Relações com o meio, atenção, voltada para si

e para o exterior:

-Fala:

.voz baixa ou forte -

fala tranquila, demorada, arrastada, rápida, fluente etc -

.aphonia -

-Mutismo:

-Repetição dos paradigmas: (libellula, flanella leve, profligar, magnificência, tres mil

trezentos e trinta e tres artilheiros da terceira brigada de

artilharia):

-Contrações correlatas dos músculos da face:

-Escripta: mediante dictado de paradigmas (artilharia, republica, appropriação,

Constitucionalismo, constantionolitano, etc.) ou espontanea: em cartas, reclamos, memorises, composições literárias, publicações, testamentos, desenhos, etc.

\section{-Logar para o autographo-}

-Correspondencia entre as ideias

setuases e a educação recebida:

-Desintegração das acquisições da

cultura intellectual:

-Calculo, religião, historia, geographia, etc:

-Memoria de factos antigos e recentes:

m. das sensações tácteis

$\mathrm{m}$. das sensações visuaes

$\mathrm{m}$. das sensações auditivas

$\mathrm{m}$. das sensações olfactivas

$\mathrm{m}$. das sensações geraes

m. affectivas

$\mathrm{m}$. das idéias 
m. da linguagem:

.lettras -

.palavras -

.phrases -

.algarismos -

-Juizo do examinado sobre si mesmo e sobre os outros:

-Súmula das acquisições que denunciam doença. Dedução diagnostica-

Os campos dessa parte do prontuário reúnem informações produzidas no período em que o paciente já se encontrava no Manicômio, com a descrição detalhada das medidas de partes de seu corpo, resultados dos testes de visão, tato, audição e olfato, observações da fala, postura, comportamento e escrita, tiques e sintomas que permitissem a correlação com doenças e degenerações físicas, psíquicas e morais. Estes, diferente da anamnese, mereciam mais atenção, recebendo registros ora protocolares, ora detalhados, o que permite observar, ao longo de um período de mais de trinta anos, quais informações e referenciais os psiquiatras julgavam mais relevantes para avaliar o paciente. Gustavo Querodia Tarelow deparou-se com uma realidade semelhante em relação aos prontuários do Juquery:

De maneira geral, os dados descritos nestes espaços buscavam legitimar as ideias de que a loucura era fruto de degeneração ou mesmo de heranças genéticas, uma vez que a psiquiatria desenvolvida naquele momento tinha suas bases no organicismo. (TARELLOW, 2011, p. 98).

O prontuário de J.F.S. exemplifica esse tipo de avaliação médica. O paciente em questão, lavrador e diagnosticado com demência precoce, não teve anotado nenhum registro nos campos de anamnese; porém, no campo de diagnóstico, o médico registrou a história narrada pelo paciente, o qual afirma que "sentia dores de cabeça quando seu cumpadre batia a enxada no chão", acreditando que as dores eram produto de "bruxaria", tomando a enxada e golpeando a cabeça do amigo. Segundo a avaliação do médico,

Lógica como está só de um cérebro doenti, entretanto, poderão nos objectar que um homem rustico, nascido longe da civilização, é sempre victima de superstições. Diremos então que não fizemos o nosso juízo sobre o paciente, só pela história que elle nos contou, mas pela observação diária a que o submetemos. Assim notamos verbigeração, perturbação da cenesthesia, allucinação auditiva billateral (...) (APESP/MJ, caixa 9, prontuário DAP 246). 
Após as páginas do "exame directo", existe um espaço para que o médico fizesse anotações, resumindo que fora mencionado nas outras páginas, facilitando a leitura pelos outros psiquiatras, visto que um mesmo paciente era atendido por diversos médicos ao longo de sua internação. Esse espaço é a "sumula das acquisições que denunciam a doença. Deducção diagnostica": apesar de ser direcionada à descrição do diagnóstico, recebia outras informações, como nesse prontuário, em que o campo foi utilizado para receber as descrições do médico de J.F.S. No fim desse item, consta novamente a foto e o "autographo" do paciente. Nele ainda poderiam estar anexados os exames aos quais o paciente fora submetido e algumas palavras do próprio paciente, descrevendo sua condição.

A segunda divisão do prontuário é o "serviço social", nela sendo anexadas as cartas e os ofícios produzidos durante o tempo de internação do paciente. Contudo, é muito comum que os anexos surjam também em outras partes do prontuário. A terceira divisão contém os documentos anteriores à internação do paciente no Manicômio. Também constam os encaminhamentos legais e jurídicos sobre o crime que o levou à internação, em alguns casos o processo criminal do paciente, transcorrido em período no qual o réu se encontrava na Penitenciária ou Cadeia Pública.

Os prontuários dos primeiros anos da instituição frequentemente eram esvaziados de informações, em alguns casos não constando uma ou duas das três pastas que compõem a fonte. Exemplo disso é o prontuário de E.A.P. (APESP/MJ, caixa 1, prontuário DAP 139), internado em 1903, que consta apenas o "arquivo psiquiátrico criminal", com poucas informações sobre a evolução do paciente no Manicômio e seus antecedentes criminais, resumidas em 12 linhas no campo "sumula das acquisições". Vale destacar que esse pequeno resumo sobre o paciente em questão foi escrito com duas letras diferentes, o que permite inferir que mais de um médico trabalhou com o paciente ou em seu prontuário. Isso também é frequente nos demais prontuários e quando trabalhamos com outros mais completos essa questão é melhor percebida. É o caso do prontuário de A.C internado em 1924, em que o campo "sumula" é preenchido por quatro médicos.

Esse modelo de prontuário prossegue desde o fím do século XIX até 1930. Acompanhando essa documentação, percebemos que a diferença entre um prontuário do começo do recorte e outro do fim, reside na organização dos documentos dentro desses prontuários e nos conteúdos, mas não na estrutura. De fato, o prontuário se mantém, em termos estruturais, praticamente o mesmo, inclusive se considerarmos a institucionalização oficial do Manicômio Judiciário em 1927 e as mudanças nas classificações das doenças 
mentais, propostas em 1910 por Juliano Moreira, membro da Sociedade Brasileira de Neurologia, Psiquiatria e Medicina Legal (SBNPML) ${ }^{8}$.

Antes de 1910, o funcionamento da instituição, sua organização e o olhar dos médicos sobre os pacientes estava pautado pelos debates da escola francesa de Pinel e Esquirol (PORTOCARRERO, 2002, p. 33), defendendo que os transtornos mentais eram originários de um corpo já doente por constituição. Assim Franco da Rocha conduziu o pensamento para a criação do Juquery, não somente na questão do diagnóstico, mas também no projeto arquitetônico do complexo hospitalar, organizado por colônias agrícolas e um hospital central. Projeto arquitetônico esse que segundo Pinel era o ideal para o tratamento daquilo que consideram moléstias mentais.

Na administração de Pacheco e Silva, a dinâmica de aplicação dos diagnósticos mudou sensivelmente, na medida em que os referencias teóricos do alienista eram distintos do seu predecessor, partindo de um olhar mais "organicista", encarando as desordens mentais como frutos de desequilíbrios orgânicos e genéticos. Silva foi influenciado pelos trabalhos do alemão Emil Kraepelin e pelos debates na SBNPML, produzindo inúmeros artigos e trabalhos científicos sobre ambos, além de estudos e apontamentos sobre a própria classificação brasileira de doenças, descrevendo seu entendimento sobre diagnósticos, por exemplo, como a demência precoce e a paralisia geral progressiva. Uma das razões pelas quais observamos um grande número de prontuários "esvaziados" nos primeiros anos do Juquery e um maior volume de informações depois de 1920 se deve ao anseio de Pacheco Silva, ao assumir a direção, em retomar a imagem do Juquery como referência na área psiquiátrica (TARELOW, 2011, p. 27). Para tanto, entre muitas medidas, ampliou a assistência clínica para os pacientes, criou novas colônias agrícolas, implementou novos cursos nas instalações laboratoriais do complexo hospitalar, destinados aos alunos de medicina que lá faziam residência, um deles o de "anatomia patológica do sistema nervoso" (TARELOW, 2011, p. 27-28).

\footnotetext{
${ }^{8}$ Constituída entre 1907 e 1928, a partir do interesse de médicos em institucionalizar a especialização em medicina-psiquiátrica. PORTOCARRERO., Vera. Arquivos da loucura: Juliano Moreira e a descontinuidade histórica da psiquiatria. Rio de Janeiro: Editora FIOCRUZ, 2002, p. 67.
} 


\section{O PRONTUÁRIO PARA ALÉM DA ESTRUTURA: POSSIBILIDADES E}

LIMITAÇÕES

A tipologia documental prontuário médico, para além dos propósitos que levam à sua produção, encontra em artigos, teses e dissertações finalidades outras, permitindo que o pesquisador tenha perspectivas ainda pouco exploradas, indo além da relação entre interno e médico. A organização desses prontuários possibilita, por exemplo, que parte do modus operandi do Manicômio Judiciário seja percebido por meio da comunicação entre a instituição e a penitenciaria ou cadeia Pública, principalmente nos casos de superlotação, quando o Manicômio se negava a receber mais pacientes. Segundo o prontuário de A.G. (APESP/MJ, caixa 5, prontuário DAP 58), em 1912 a instituição enfrentava uma gravíssima situação de lotação e falta de recursos, e o paciente precisou aguardar a disponibilidade de vaga.

A comunicação interna na instituição, entre direção e médicos, pacientes e direção, médicos e pacientes, também permite discutir a divisão dos espaços do Complexo Hospitalar do Juquery por exemplo, a existência de colônias agrícolas no entorno do Manicômio, o Hospital Central, as alas cirúrgicas, o Manicômio etc. Clementina Cunha (2010, p. 54-55) discute a suposta "ascensão" do paciente enquanto estava internado, sendo a colônia o momento de maior liberdade e a permanência no hospício a mais opressiva. Mesmo que a autora tenha usado a documentação do Hospital Psiquiátrico Juquery e não a do Manicômio Judiciário, os prontuários médicos aqui utilizados trazem informações que permitem a comparação com o retrato institucional e terapêutico produzido no trabalho de Cunha.

Além dos ofícios anexados aos prontuários permitindo o estudo sobre a organização da instituição, o "arquivo psiquiátrico-criminal” reúne em sua primeira página, como já foi dito, um conjunto de informações para a identificação do paciente. Esses mesmos dados podem ser utilizados, hoje, como uma ferramenta para levantamentos demográficos, que possibilitam discutir o perfil social dos pacientes internados baseados em questões como idade, sexo, etnia, procedência, religião, ocupação, naturalidade e instrução. Esse tipo de abordagem pode ser útil em estudo dos tipos sociais marginalizados pelas instituições de poder. Nesse sentido, as possibilidades são diversificadas: levantamentos sobre o índice de analfabetismo em pacientes de instituições psiquiátricas, os tipos de trabalho ou ofício mais comuns, as religiões que mais eram mencionadas, os grupos étnicos com maior entrada na instituição. A "loucura" era um problema de fora que veio para o Brasil? Nas primeiras décadas da República argumenta-se 
que sim (ENGEL, 2001, p. 176) , ou que a "loucura" era exclusiva de determinadas nacionalidades, e a produção de um levantamento dos imigrantes e brasileiros internados poderia problematizar o tema.

A documentação também tem importância para os que se interessam pelos estudos de sexualidade e gênero, principalmente quando analisada em conjunto com outros documentos, por exemplo, os prontuários do Hospício do Juquery e os do Pinel. Esse último, de caráter particular, portanto, com critérios de internação distintos do Manicômio Judiciário, pode ser interessante para uma análise comparativa das diferenças entre o número de mulheres e homens internados em cada uma das instituições e tratamento dispensado a ambos.

Ainda no que se refere aos perfis sociais e demográficos, os interessados na história da criminalidade podem encontrar nos prontuários do Manicômio Judiciário quais eram os crimes mais comumente condenados. Muitos estudos sobre o tema debruçaram-se sobre as fichas criminais da Penitenciária do Estado, e o recurso aos prontuários pode oferecer um complemento para essas pesquisas. Não podemos esquecer também os estudos sobre a doença mental em São Paulo.

A documentação manicomial também tem muito a oferecer aos pesquisadores que discutem o avanço do cientificismo na medicina legal e da psiquiatria como modalidade de controle social, principalmente se levarmos em conta o grande contingente humano internado durante os primeiros trinta anos do século XX. Nos prontuários, há indícios de quais setores da sociedade foram mais sujeitos à internação, além das principais práticas hospitalares envolvidas.

Uma das possibilidades ainda pouco exploradas é o levantamento das principais terapias medicamentosas aplicadas nos pacientes e os tratamentos mais comuns ${ }^{10}$. Os prontuários possuem um receituário na parte destinada ao "serviço social" em que reunia os medicamentos que os pacientes recebiam, assim como as cirurgias às quais eram submetidos enquanto internados. Infelizmente, porém, nem todos os prontuários possuem essa ficha.

\footnotetext{
9 A autora destaca um trecho de um artigo médico escrito por Juliano Moreira em 1922, no qual o médico defende politicas higienistas específicas para imigrantes, a fim de evitar que esses entrassem no pais na condição de doentes mentais, degenerados e iletrados. Além desse artigo, mais trabalhos sobre a questão do imigrante foram produzidos por alienistas e psiquiatras. É preciso destacar que muitos desses estavam sob a influência de Juliano Moreira e seu trabalho no Hospital de Alienados, antigo Hospital D. Pedro II. Ver mais em: PORTOCARRERO, Vera. Arquivos da loucura: Juliano Moreira e a descontinuidade histórica da psiquiatria. Rio de Janeiro: Editora FIOCRUZ, 2002.

10 Em CUNHA, Maria Clementina Pereira. Cidadelas da ordem: a doença mental na República. São Paulo: Brasiliense, 2010, dedicara-se, em parte, a trabalhar essas questões, e em muito essa discussão pode ser aprofundada utilizando-se da documentação do Manicômio.
} 
Outro potencial dessa documentação é possibilidade de buscar nela traços dos pacientes em um documento produzido por mãos médicas. Encontrar com clareza a voz do paciente pode ser difícil, mas em alguns momentos o paciente escreve de próprio punho o modo como interpreta sua internação no Manicômio ou o diagnóstico que os médicos lhe dão, e esse depoimento acaba se misturando com as anotações dos psiquiatras. A perspectiva do paciente também pode ser observada nas cartas aos familiares ou aos médicos, sendo que em alguns casos o paciente tenta convencer o diretor de sua recuperação e lucidez. Os pacientes eram encorajados a produzirem cartas, uma vez que no item "exame mental", das páginas do "exame direto"11, os médicos eram instruídos a testarem a escrita dos pacientes pedindo que redigissem as seguintes palavras: "artilharia, republica, appropriação, constitucionalismo, constantinopolitano (...)" ou então que fossem recolhidos os escritos "voluntários" dos pacientes, entre eles cartas, textos, produções literárias e bilhetes.

P.G.M. (APESP/MJ, caixa 15, prontuário DAP 147) foi um dos vários pacientes que escrevia cartas a seus familiares. Em uma delas, pediu que sua esposa queimasse seu diploma de professor e de maçom, afirmando que não tinha religião e era anarquista, mas que se possível ela the enviasse uma Bíblia para ele estudar. Os médicos buscavam muito mais do que caligrafia nas cartas: a produção dos pacientes era analisada na busca de sintomas. Evidentemente alguns pacientes sabiam disso. Outro caso envolvendo a expressão de um paciente deu-se com A.P. (APESP/MJ, caixa 13, prontuário DAP 33), nesse caso carta e desenhos. O prontuário reuniu algumas fotos, sendo a primeira aparentemente uma carta destinada ao diretor da Penitenciária na qual o paciente afirma ter sido reprimido por defender o espiritismo e questiona sua sentença. A segunda é o desenho de um cavalo com vestimenta que aparenta ser a de um bispo. A terceira tem um homem deitado numa mesa gritando "espiritismo" e um homem em pé ao seu lado, com vestimenta de clérigo, onde se lê "catolicismo", examinando-o. Sobre o homem deitado, está escrito "art. 294" e, ao lado do clérigo, "art. 55", e sobre ambos cai água saindo de uma torneira. No lado direito desses homens há um índio "potiguara"12 apontando para eles. Na quarta foto há um pescador ao lado de um cachorro, onde lemos uma frase aclamando Julio Prestes, figura pública no cenário paulista e brasileiro durante os primeiros trinta anos da recente república, e um tal de "Laurindo Manhoto".

As limitações dessa fonte acompanham suas possibilidades. Explico: as cartas presentes nos prontuários oferecem possibilidades para o estudo da perspectiva do paciente,

${ }^{11}$ Como apresentado acima, na transcrição das do prontuário.

${ }^{12}$ Assim é descrito no prontuário. 
mas elas passavam pelo crivo dos médicos, e algumas eram removidas dos prontuários. Isso pode limitar o estudo dos prontuários quando tomados em série. Posto isso, a principal limitação da documentação são seus longos intervalos cronológicos sem preenchimento e o desconhecimento do volume total do acervo. Em parte, isso se deve aos problemas de acondicionamento do arquivo no Manicômio Judiciário. Trabalhar com os prontuários do Manicômio Judiciário de São Paulo significa lidar com informações que, embora devessem ser seriais, mostram-se muito diferentes, não apenas nas lacunas de informações, mas nos tipos de documentos anexados e na ausência de páginas em alguns deles. Existem prontuários com fotos dos pacientes e páginas do "arquivo psiquiátrico- criminal" removidas, podendo este fato vir a ser um fator limitante. Contudo, lacunas e silêncios também podem dizer muito ao historiador sobre os responsáveis pela produção da documentação e sua salvaguarda. Também há intencionalidades nos espaços em branco.

\section{REFERÊNCIAS BIBLIOGRÁFICAS}

BERTOLLI FILHO, Claudio. Prontuários médicos: fonte para o estudo da história social da medicina e da enfermidade. História, Ciências, Saúde-Manguinhos, Rio de Janeiro, v. 3, n.1, p. 173-180, 1996.

CANOVA, Loiva. A questão da loucura na historiografia ocidental e nos jornais da cidade de Cuiabá na Primeira República. Cordis. História, Corpo e Saúde, no 7, p. 185-218, jul./dez, 2011.

CUNHA, Maria Clementina Pereira. Cidadelas da ordem: a doença mental na República. São Paulo: Brasiliense, 2010.

CUNHA, Maria. Clementina Pereira. P. O espelho do mundo. Juquery, a história de um asilo. Rio de Janeiro: Paz e Terra, 1986.

ENGEL, MG. Os delírios da razão: médicos, loucos e hospícios (Rio de Janeiro, 18301930). Rio de Janeiro: Editora FIOCRUZ, 2001. 
FERLA, Luis Antonio Coelho. Feios, sujos e malvados sob medida. Tese (Doutorado em História Social), São Paulo: Faculdade de Filosofia, Letras e Ciências Humanas da Universidade de São Paulo. São Paulo, 2005.

NEVES, Afonso Carlos. A construção do corpo psiquiátrico. In MOTA, André (ORG).

História da Psiquiatria: Ciência, práticas e tecnologias de uma especialidade médica. São Paulo: USP, Faculdade de Medicina: UFABC, Universidade federal do ABC: CD.G Casa de Soluções e Editora, 2012.

OLIVEIRA, Carlos Francisco Almeida de. Evolução das classificações psiquiátricas no Brasil: um esboço histórico. Dissertação (Mestrado em História), São Paulo: Unicamp, 2003.

PORTOCARRERO., Vera. Arquivos da loucura: Juliano Moreira e a descontinuidade histórica da psiquiatria. Rio de Janeiro: Editora FIOCRUZ, 2002.

Resolução SC n. ${ }^{\circ}$ 13, de 09/03/2011, publicado no DOE de 31/03/2011, pag. 203 (Republicado em 17/05/2011, pag. 37, com mapa). Disponível em: http://dobuscadireta.imprensaoficial.com.br/?\&NumeroPagina $=37 \&$ DataPublicacao $=2011051$ 7\&Caderno=executivo). Acessado em: 10/10/2015

SANTOS, Nádia Maria Weber. Histórias de Sensibilidades: Espaços e Narrativas da Loucura em Três Tempos. 2005. 385p. Tese de conclusão de curso (História) - Universidade Federal do Rio Grande do Sul. Porto Alegre. 2005. Disponível em: https://www.lume.ufrgs.br/bitstream/handle/10183/12741/000474599.pdf?sequence=1. Acessado em: 10/03/2017.

SÃO PAULO. Secretaria de Estado da Cultura de São Paulo. Condephaat - Parecer Técnico UPPH N ${ }^{\circ}$ GEI-7-2009. Estudo de tombamento do Hospital do Juquery (conjunto arquitetônico, acervo documental e área verde existente) - Franco da Rocha. Disponível em: https://raquelrolnik.files.wordpress.com/2010/12/condephaat-resolucao-tombamentopacaembu-jardins.pdf. Acessado em: 10/10/2015.

SCOTTI, Zelinda Rosa. Os prontuários do Hospício São Pedro: metodologia para formação de banco de dados. Revista Ágora, n. ${ }^{\circ} 12$, Vitória, p.1-12, 2011. 
TARELOW, Gustavo Querodia. Entre febres, comas e convulsões: as terapias biológicas no Hospital do Juquery administrado por Pacheco e Sila (1923-1937). 2012, 198 p. Dissertação (Mestrado em história social). São Paulo: Faculdade de Filosofia, Letras e Ciências Humanas. da Universidade de São Paulo, 2012. Disponível em:

http://www.teses.usp.br/teses/.../8/.../2011_GustavoQuerodiaTarelow_VOrig.pdf São Paulo, 2011. Acessado em 9/10/2015.

VIANA, Bruna da Silveira. Salvaguarda e possibilidades de pesquisa: os prontuários do antigo hospital colônia sant'ana. I Simpósio de Patrimônio Cultural de Santa Catarina "Patrimônio Cultural: Saberes e Fazeres Partilhados", Florianópolis, SC, p. 1 - 10, 21 e 22 de novembro de 2013,

WADI, Yonissa. Marmitt. A história de Pierina: subjetividade, crime e loucura. Uberlândia: EDUFU, 2009. 